\title{
Analysis of Wear Behaviour of AA5052 Alloy Composites by Addition Alumina with Zirconium Dioxide Using the Taguchi-Grey Relational Method
}

\author{
Bhiksha Gugulothu $\mathbb{D}^{1},{ }^{1}$ S. Lakshmi Sankar, ${ }^{2}$ S. Vijayakumar $\mathbb{D}^{3},{ }^{3}$ \\ Adina Srinivasa Vara Prasad, ${ }^{3}$ M. Thangaraj, ${ }^{4}$ M. Venkatachalapathy, ${ }^{5}$ \\ and T.V.Janardhana Rao ${ }^{6}$ \\ ${ }^{1}$ Department of Mechanical Engineering, Bule Hora University, Post Box No-144, Bule Hora, Ethiopia \\ ${ }^{2}$ School of Mechanical Engineering, Sathyabama Institute of Science and Technology, Chennai, India \\ ${ }^{3}$ Department of Mechanical Engineering, BVC Engineering College (Autonomous), Odalarevu-533210, Andhra Pradesh, India \\ ${ }^{4}$ Department of Physics, PSNA College of Engineering and Technology, Dindigul-624622, India \\ ${ }^{5}$ Department of Mathematics, K.Ramakrishnan College of Engineering, Trichy, India \\ ${ }^{6}$ Department of Electronics and Communications Engineering, BVC Engineering College (Autonomous), Odalarevu-533210, \\ Andhra Pradesh, India
}

Correspondence should be addressed to Bhiksha Gugulothu; bhikshamg@bhu.edu.et

Received 3 December 2021; Accepted 8 February 2022; Published 3 March 2022

Academic Editor: Qian Chen

Copyright (c) 2022 Bhiksha Gugulothu et al. This is an open access article distributed under the Creative Commons Attribution License, which permits unrestricted use, distribution, and reproduction in any medium, provided the original work is properly cited.

\begin{abstract}
The present study deals with preparation of Al hybrid metal matrix composites by the stir casting technique. In this work, Al5052 alloy was selected as the main metal which reinforces with zirconium dioxide and aluminium oxide. The wear test has been conducted on the POD apparatus. 9 specimens are produced by varying reinforcements' percentage for conduction of tests. The amount of $\mathrm{ZrO}_{2}$ reinforcement is fixed to $8 \mathrm{wt} \%$, while the concentration of $\mathrm{Al}_{2} \mathrm{O}_{3}$ varied from $5 \mathrm{wt} \%$ to $10 \mathrm{wt} \%$. The parametric optimization of wear behaviour is done through the Taguchi method with L9 orthogonal array. Minitab statistical software helped to find SN ratio and ANOVA reading for each parameter: load $(\mathrm{N})$, sliding speed (rpm), and wt\% of reinforcements. From the ANOVA outcome, the load parameter is the highest influencing element that improves wear resistance of made samples around $46 \%$, followed by weight $\%$ of reinforcement $29 \%$ and sliding speed $26 \%$ as second and third influenced parameters, respectively.
\end{abstract}

\section{Introduction}

The preparation of machineries, products, and any shape of items has been carried out using the stir casting procedure. This method is relevant to dimensions and volume of \% weight on reinforcements [1, 2]. The samples of AL6082/Tic are produced by liquid metallurgy, and many tests are conducted to analyse behaviour of materials [3]. Laser methodology was also used sometimes to make composites, for example, Al-Gr metal alloy was prepared in that way, the element of $\mathrm{Gr}$ augmented the wear resistance property in final result [4]. Aluminium-based alloy 5052 which is named as aluminium-Mg alloy belonging to 5000-series category possesses more resist from oxidization. It is able to give high wear behaviour during ionization of surface film [5].

Zirconium dioxide is acting like a glowing particle that is mostly present in earth in the form crystalline structure $[6,7]$. Aluminium oxide also called as alumina or Al oxide or aloxite is useful for producing AA-depended items [8]. $\mathrm{Al}_{2} \mathrm{O}_{3}$ was acknowledged in $\alpha$-level which is suitable in pads (electrically padding) manufactured as well as cutting tool abrasive parts in mechanical field [9]. The research work of Ranjan et al. done on Al-356 along with a nanoalumina/ $\mathrm{ZrO}_{2}$ (micro) hybrid composite specimens is made by 
squeeze casting. The result of corrosion resistance and hardness of ready samples are improved by rising ceramic reinforcement's percentage [10]. In another article of AL5052/zirconium oxide, $\mathrm{HV}$, microhardness and rate of wear were investigated after standard dimension of samplings. From the output reading, it was noticed that $\mathrm{HV}$ improved from around 75 to 115 [11]. The change of $\mathrm{ZrO}_{2}$ wt\% level leads to change of the effect of behaviour of $\mathrm{Al}$ alloy (6061). Variation of zirconium oxide ranges with fly-ash approximately $5-10 \%$ that tends of increasing abrasion values $(95 \mathrm{Hv})$ and tensile strength $(280 \mathrm{MPa})$, and elongation (22\%) expressively decreases due to addition of these particulates of $\mathrm{ZrO}_{2}$ /ash content [12]. Girisha and others have done an experiment on aluminium 356 with oxide of zirconium particle accumulation [13]. $\mathrm{ZrB}_{2}$ has been utilized as AMC reinforcement, giving more strength of tensile by increasing from 10 to $15 \mathrm{wt} \%$ fraction [14]. Generally, density of AMCs materials reduced while adding $\mathrm{TiO}_{2}, \mathrm{TiB}_{2}$, and other particulates of oxide particles, but when adding fly-ash, RH ash and mica more balance to reduce weight of making components [15]. Value of wear property on both wet and dry conditions gets increased due to higher grain size of graphite $5 \mathrm{wt} \%$ in Al-Gr combination alloy [15]. Mostly, corrosion characterises depending on slide speed, pin-on-disc diameter, and load parameters. Mass in wear was found decreased by increasing extra speed of disc, and $\mathrm{COF}$ reductions by graphite accumulation were observed in AA-7075 [16]. LM6 alloy reinforced alumina $\mathrm{Al}_{2} \mathrm{O}_{3}$ elements in different fraction volumes (0.05-0.15 wt), and sizes of (44-125lm) samples were being generated via the PDC technique [17]. The defects on prepared specimens can be found by conducting nondestructive testing [18]. The radiography test is a kind of NDT used for analysing defects present on welding plates of SS304 [19]. The EDs test is also utilized to check microstructure and chemical composition of objects $[20,21]$. This kind of prepared AA 5052 with reinforcement composites were used in many applications such as pressure vessels, making the equipment in marine field, chassis in electronic arena, hydraulic type tubes, and also apparatus in medical domains.

From the various literature review articles, our intention is to create many $\mathrm{Al}$ alloy samples with different parameters. Statically, Minitab software was used to execute design of experiments on wear parameters.

\section{Procedure for Experimentation}

The initial stage has to be metal collection and then start making sample on Al5052 in a stir-cast procedure. Subsequently prepared specimens with ASTM standards were taken to conduct examinations for analyse characterises. The cast process is mostly used to produce the desired shape of objects through mold parts. In this experimental work, the stirrer is made by stainless steel as a main part, mixing $\mathrm{Al}$ alloy and selected reinforcements at particular speeds. Rotation of the stirrer is maintained around $600-800 \mathrm{rpm}$, by inserting the furnace that manage heat to melting of solid metal and powders. Before addition particulates, zirconium dioxide and aluminium oxide in 5052 alloy in the crucible need to be preheated at $350^{\circ} \mathrm{C}$. Three import parts available in stir position are the solid rod and impeller with angle of blades.

The motor is a source which supplies the power to stir the rod to perform mixing operations of materials once conversion of solid into liquid (molten metal) is done and poured to designed dies. The total setup of furnace with other parts is shown in Figure 1, and also, elements of 5052 $\mathrm{Al}$ are given in Table 1.

Smooth cleaning or polish of work piece is most important to remove unnecessary chips from surfaces. This process can be done by application of some solvents or sand papers. Those samples are kept on the POD apparatus with DOE orthogonal array (L9); material is removed from alloy metal due to abrasion between disc and AL samplings; in the entire procedure, weight before and after experiments needs to measured. For analysis of corrosion behaviour optimization, three levels have been selected on three parameters load: Ld (20, 25, and $30 \mathrm{~N}$ ), sliding velocity Sd (300, 400, and $500 \mathrm{rpm})$, reinforcements Rt (5-10\%w.t) as given in Table 2. Signal-to-noise and wear performance readings are given in Table 3 .

\section{Result and Discussion}

Nine wear experiments are conducted on the POD machine from those wear results (Table 3) design of experiments carried out by giving various input factors on optimize software (Minitab 18). The responding mean and SN ratio are shown in Figure 2 and Figure 3. Optimum wear behaviour was observed at third levels of load ( ${ }^{\text {st }}$ rank) and reinforcement wt $\left(2^{\text {nd }}\right.$ rank) and $2^{\text {nd }}$ level in sliding speed $\left(3^{\text {rd }}\right.$ rank), as given in Table 4 and Table 5.

A contribution of each parameter on ANOVA results has been calculated, and the load is a major contributed factor that influenced wear performance about 45.12\%; next, substantial parameter is reinforcement percentage of $\mathrm{ZrO}_{2} /$ $\mathrm{Al}_{2} \mathrm{O}_{3}$, which contributed around $29.48 \%$, and sliding speed is the last influencing factor that considered $25.40 \%$ for wear rate (Table 6).

The lowest SN ratio among all chosen factors is 41.92, identified at load level 1 , but at the same time, the highest value was also found in level 3 long with delta 2.73 (Table 4). The response of mean given in Table 5 provides that Ld level 2 is more compared to other levels of Sd and Rt. The minimum wear rate $\left(0.00432 \mathrm{~mm}^{3} / \mathrm{Nm}\right)$ has found the combination of load $(25 \mathrm{~N})$, sliding speed $(300 \mathrm{rpm})$, and weight percentage reinforcement $(5 \%)$. The predicted regression equation for wear rate obtained from Minitab 18 is exposed as in the following equation:

Wear rate $=0.01017-0.000093 \mathrm{Ld}+0.000004 \mathrm{Sd}-0.000314 \mathrm{Rt}$.

The surface plot for wear performance against Ld, Sd, and $\mathrm{Rt}$ is drawn. It was noticed that rate or value of wear increased with increased slide speed and decrement of load (Figure 4); at the same way, wear value slightly comes down due to increase of reinforcement and load (Figure 5), and finally, wear rate was changed while changing of reinforcement $\%$ and Sd (Figure 6). 


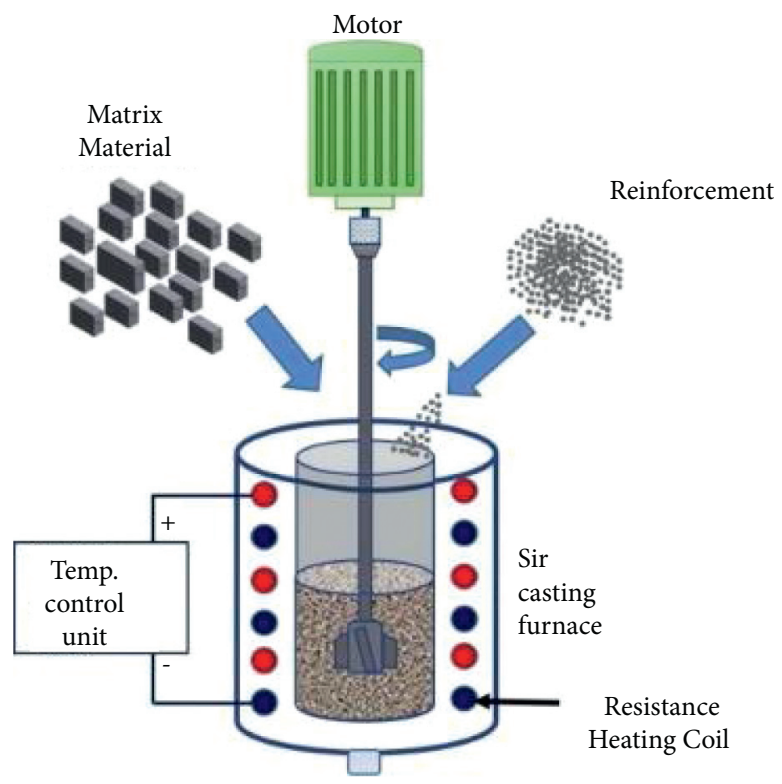

FIGURE 1: Stir casting furnace.

TABLE 1: Composition AA5052 (\% wt).

\begin{tabular}{lcccccccc}
\hline Materials & $\mathrm{Si}$ & $\mathrm{Cu}$ & $\mathrm{Fe}$ & $\mathrm{Mg}$ & $\mathrm{Cr}$ & $\mathrm{Mn}$ & $\mathrm{Zn}$ & $\mathrm{Al}$ \\
\hline Percent & 0.25 & 0.12 & 0.39 & 2.5 & 0.21 & 0.1 & 0.15 & Balance \\
\hline
\end{tabular}

TABLE 2: Stages in test factors.

\begin{tabular}{lccc}
\hline Parameters: & Level 1 & Level 2 & Levels 3 \\
\hline Ld (N) & 20 & 25 & 30 \\
Sd (rpm) & 300 & 400 & 450 \\
Rt (wt\%) & 5 & 7.5 & 10 \\
\hline
\end{tabular}

TABLE 3: Observation results.

\begin{tabular}{|c|c|c|c|c|c|}
\hline Exp. no. & Ld $(\mathrm{N})$ & $\mathrm{Sd}(\mathrm{rpm})$ & Rt (wt\%) & Wear rate $\left(\mathrm{mm}^{3} / \mathrm{Nm}\right)$ & SN ratio \\
\hline 1 & 20 & 300 & 5 & 0.00735 & 42.6743 \\
\hline 2 & 25 & 400 & 7.5 & 0.00526 & 45.5803 \\
\hline 3 & 30 & 500 & 10 & 0.00814 & 41.7875 \\
\hline 4 & 30 & 300 & 5 & 0.00949 & 40.4547 \\
\hline 5 & 20 & 400 & 7.5 & 0.00615 & 44.2225 \\
\hline 6 & 25 & 500 & 10 & 0.00882 & 41.0906 \\
\hline 7 & 25 & 300 & 5 & 0.00432 & 47.2903 \\
\hline 8 & 30 & 400 & 7.5 & 0.00715 & 42.9139 \\
\hline 9 & 20 & 500 & 10 & 0.00649 & 43.7551 \\
\hline
\end{tabular}

The lowest SN ratio among all chosen factors is 41.92 , identified at load level 1; but at the same time, the highest value was also found in level 3 long with delta 2.73 (Table 4). The response of mean given in Table 5 provides that Ld level 2 is more compared to other levels of Sd and Rt. From Table 6, result of ANOVA, it was observed that $F$ value is higher at load (0.85) factor compared to other remaining factors, so that contribution of $\mathrm{Ld}$ is most influenced in wear performance. 


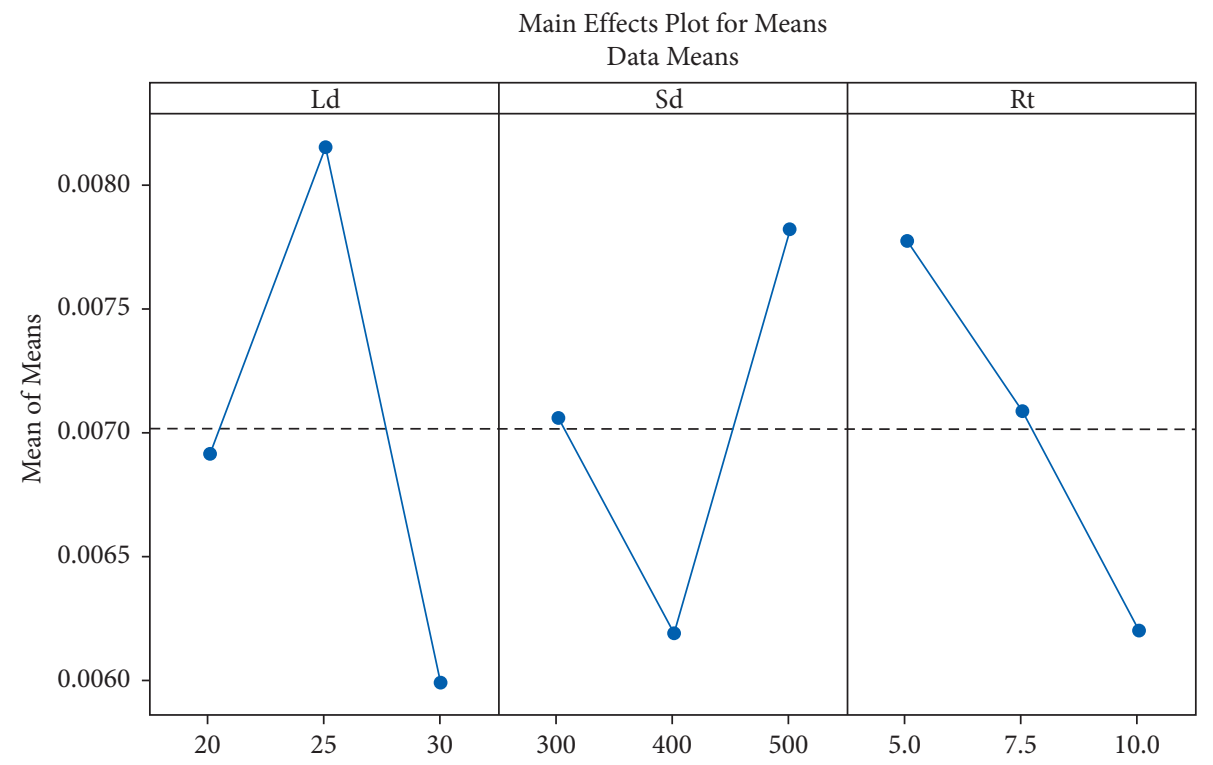

FIGURE 2: WR means plot.

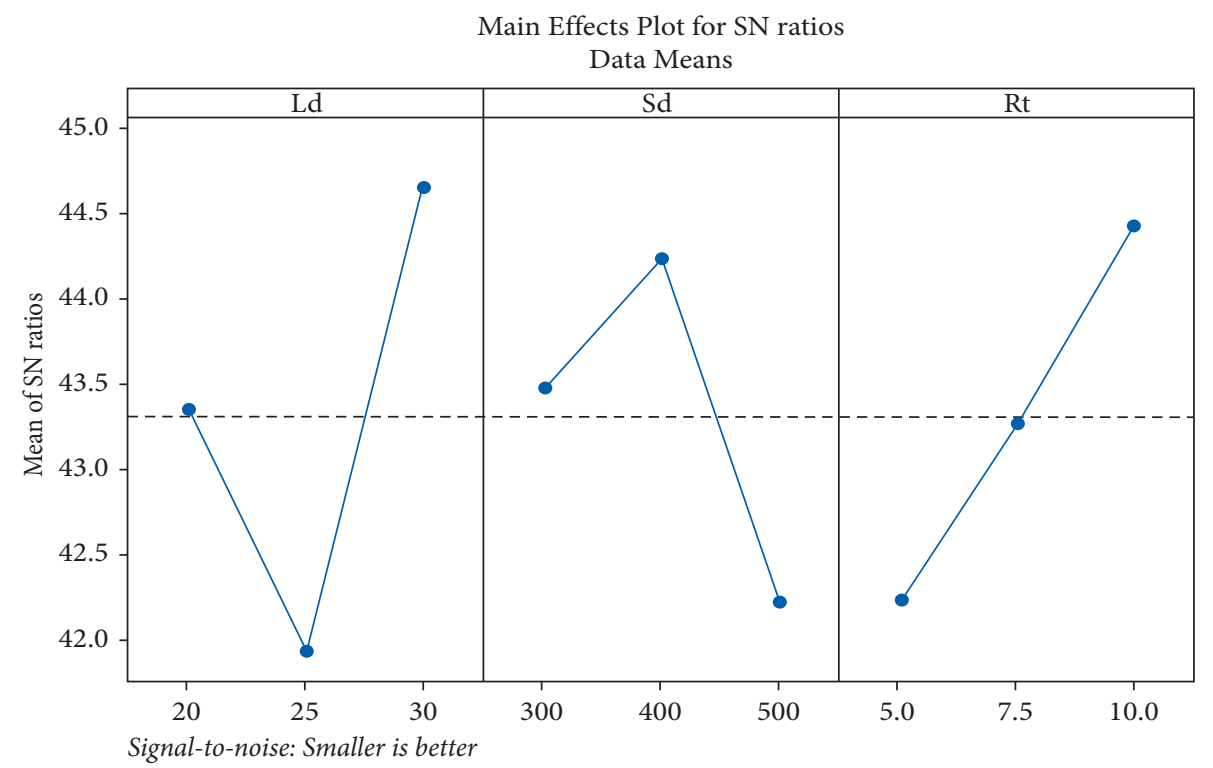

FIgURE 3: WR-SN plot.

TABLE 4: Responses signal-to-noise ratios.

\begin{tabular}{lccc}
\hline Level & Ld & Sd & Rt \\
\hline 1 & 43.35 & 43.47 & 42.23 \\
2 & 41.92 & 44.24 & 43.26 \\
3 & 44.65 & 42.21 & 44.43 \\
Delta & 2.73 & 2.03 & 2.21 \\
Rank & 1 & 3 & 2 \\
\hline
\end{tabular}


TABle 5: Responses means.

\begin{tabular}{lccc}
\hline Level & Ld & Sd & Rt \\
\hline 1 & 0.006917 & 0.007053 & 0.007773 \\
2 & 0.008153 & 0.006187 & 0.007080 \\
3 & 0.005987 & 0.007817 & 0.006203 \\
Delta & 0.002167 & 0.001630 & 0.001570 \\
Rank & 1 & 2 & 3 \\
\hline
\end{tabular}

TABLE 6: ANOVA result.

\begin{tabular}{lcccccc}
\hline Sources & Degree of freedom (DF) & Squares sum (seq SS) & Mean square (adj MS) & F value & $P$ value & Contribute level (\%) \\
\hline Ld & 2 & 11.191 & 5.595 & 0.85 & 0.541 & 45.12 \\
Sd & 2 & 6.291 & 3.146 & 0.48 & 0.677 & 25.40 \\
Rt & 2 & 7.316 & 3.658 & 0.55 & 0.643 & 29.48 \\
\hline
\end{tabular}

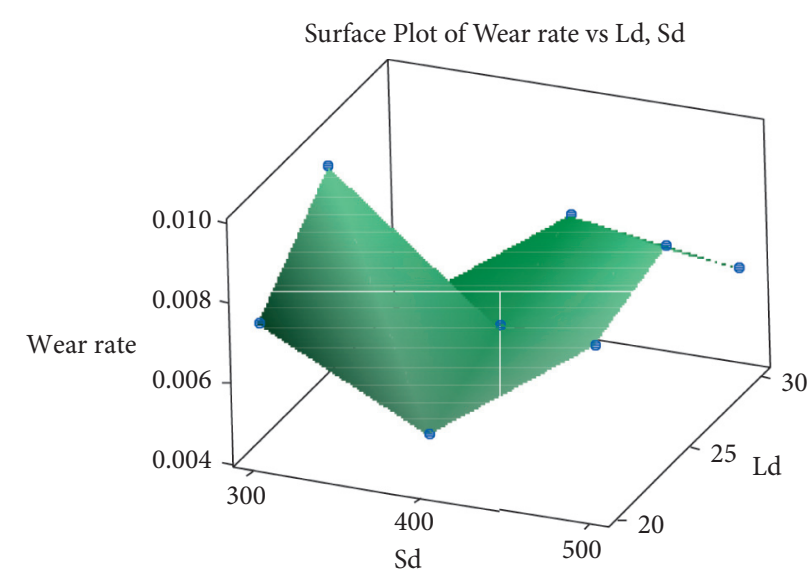

FIgURE 4: Plot of Ld, slide speed versus WR.

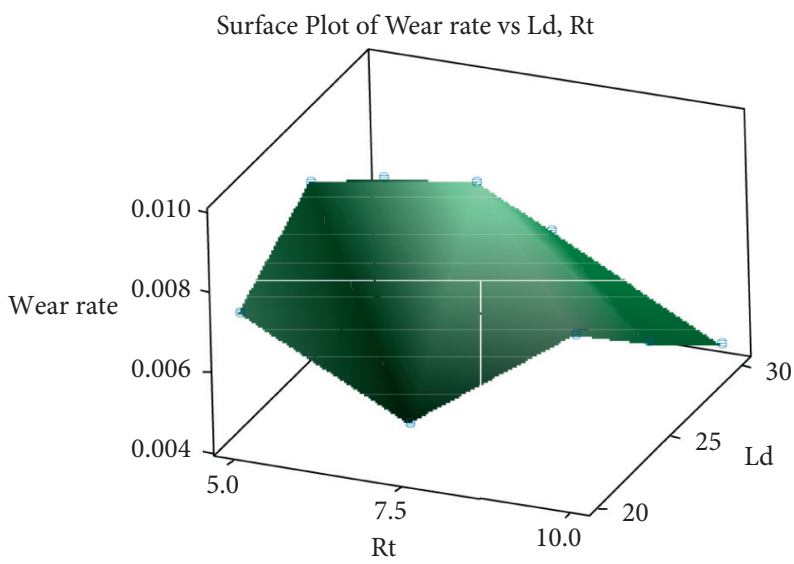

FIgURE 5: Plot of WR versus Ld and Rt. 


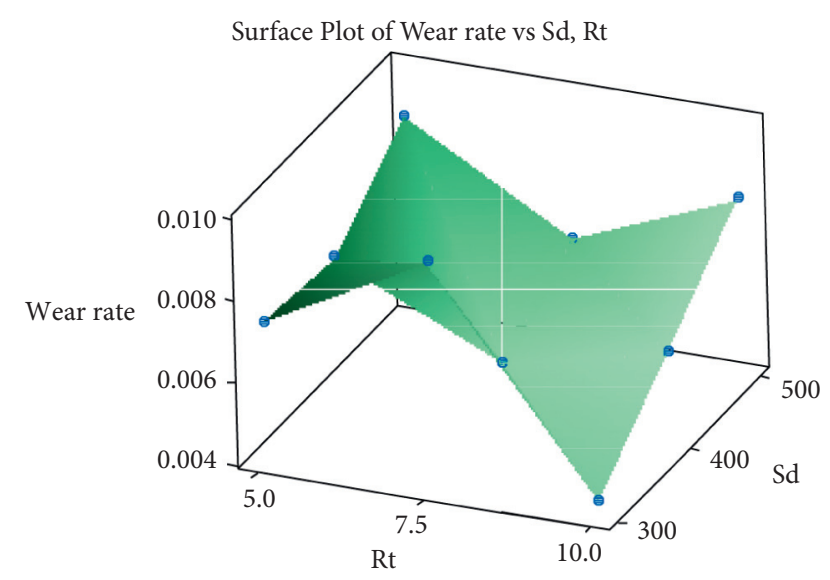

FIGURE 6: Plot on wear rate versus Sd and Rt.

\section{Conclusion}

Al 5052 alloy is main material which reinforced with zirconium dioxide and alumina. Nine specimens are prepared as per ASTM standard by the help of the stir casting technique to conduct the wear test on pin-on-disc (POD). Design of experiments for wear parameters have been analyzed via the Minitab optimize software. It is observed that load is leading parameter that influences wear behaviour of prepared samples about $45.12 \%$; weight percentage of reinforcements (29.48\%), and sliding speed (25.40\%) are considered as second and last influence factors, respectively, in wear rate performance. Finally, the least wear rate is obtained in the combination of $25 \mathrm{~N}$ load, $300 \mathrm{rpm}$ sliding speed, and $5 \mathrm{wt} \%$ of reinforcement.

\section{Data Availability}

The data used to support the results of this study are included within the article and are available from the corresponding author upon request.

\section{Disclosure}

It was performed as a part of the employment in Bule Hora University, Ethiopia.

\section{Conflicts of Interest}

The authors declare that there are no conflicts of interest.

\section{Acknowledgments}

The authors appreciate the technical assistance to complete this experimental work from Department of Mechanical Engineering, Bule Hora University, Ethiopia. The authors thank the Department of Mechanical Engineering, BVC Engineering College (Autonomous), Andhra Pradesh, and Department of Physics, PSNA Engineering College, Tamil Nadu, India, and Department of Mathematics, K. Ramakrishnan College of Engineering, Trichy, India, for the support of draft writing.

\section{References}

[1] V. Mohanavel, S. S. Kumar, T. Sathish, T. Adithiyaa, and K. Mariyappan, "Microstructure and mechanical properties of hard ceramic particulate reinforced AA7075 alloy composites via liquid metallurgy route," Materials Today Proceedings, vol. 5, no. 13, pp. 26860-26865, 2018.

[2] M. Ravichandran and S. Dineshkumar, "Experimental investigations of $\mathrm{Al}-\mathrm{TiO} 2-\mathrm{Gr}$ hybrid composites fabricated by stir casting," Materials Testing, vol. 58, no. 3, pp. 211-217, 2016.

[3] K. Ravikumar, K. Kiran, and V. S. Sreebalaji, "Characterization of mechanical properties of aluminium/tungsten carbide composites," Measurement, vol. 102, pp. 142-149, 2017.

[4] Y. B. Liu, J. D. Hu, Z. Y. Cao, and P. K. Rohatgi, "Wear resistance of laser processed $\mathrm{Al}-\mathrm{Si}$-graphitep composites," Wear, vol. 206, no. 1-2, pp. 83-86, 1997.

[5] V. K. Parikh, A. D. Badgujar, and N. D. Ghetiya, "Joining of metal matrix composites using friction stir welding: A review," Materials and Manufacturing Processes, vol. 34, no. 2, pp. 123-146, 2019.

[6] Y. Anand and V. Dutta, "Testing of composites: A review," International Journal of Advanced Materials Manufacturing and Characterization, vol. 3, no. 1, pp. 359-363, 2013.

[7] A. Akinci, S. Sen, and U. Sen, "Friction and wear behavior of zirconium oxide reinforced PMMA composites," Composites Part B: Engineering, vol. 56, pp. 42-47, 2014.

[8] E. R. I. Mahmoud, M. Takahashi, T. Shibayanagi, and K. Ikeuchi, "Wear characteristics of surface-hybrid-MMCs layer fabricated on aluminum plate by friction stir processing," Wear, vol. 268, no. 9-10, pp. 1111-1121, 2010.

[9] A. Shafiei-Zarghani, S. F. Kashani-Bozorg, and A. ZareiHanzaki, "Wear assessment of $\mathrm{Al} / \mathrm{Al} 2 \mathrm{O} 3$ nano-composite surface layer produced using friction stir processing," Wear, vol. 270, no. 5-6, pp. 403-412, 2011.

[10] S. Malhotra, R. Narayan, and R. D. Gupta, "Synthesis and characterization of aluminium 6061 alloy-flyash \& zirconia metal matrix composite," International Journal of Current Engineering and Technology, vol. 3, no. 5, pp. 1716-1719, 2013.

[11] K. B. Girisha and H. C. Chittappa, "Preparation, characterization and wear study of aluminium alloy (Al 356.1) reinforced with zirconium nano particles," International Journal of Innovative Research in Science, Engineering and Technology, vol. 2, pp. 3627-3637, 2013.

[12] S. D. Kumar, M. Ravichandran, and M. Meignanamoorthy, "Aluminium metal matrix composite with zirconium diboride reinforcement: A review," Materials Today Proceedings, vol. 5, no. 9, pp. 19844-19847, 2018.

[13] J. Singh and A. Chauhan, "Characterization of hybrid aluminum matrix composites for advanced applications - A review," Journal of Materials Research and Technology, vol. 5, no. 2, pp. 159-169, 2016.

[14] F. Akhlaghi and A. Zare-Bidaki, "Influence of graphite content on the dry sliding and oil impregnated sliding wear behavior of $\mathrm{Al}$ 2024-graphite composites produced by in situ powder metallurgy method," Wear, vol. 266, no. 1-2, pp. 37-45, 2009.

[15] F. Gardea and D. C. Lagoudas, "Characterization of electrical and thermal properties of carbon nanotube/epoxy composites," Composites Part B: Engineering, vol. 56, pp. 611-620, 2014. 
[16] P. Paramasivam and S. Vijayakumar, "Mechanical characterization of aluminium alloy 6063 using destructive and nondestructive testing," Materials Today Proceedings, 2022.

[17] A. P. Pasupulla, H. A. Agisho, S. Seetharaman, and S. Vijayakumar, "Characterization and analysis of TIG welded stainless steel 304 alloy plates using radiography and destructive testing techniques," Materials Today Proceedings, vol. 51, pp. 935-938, 2021.

[18] H. P. Pydi, A. P. Pasupulla, S. Vijayakumar, and H. A. Agisho, "Study on microstructure, behavior and $\mathrm{Al}_{2} \mathrm{O} 3$ content flux A-TIG weldment of SS-316L steel," Materials Today Proceedings, vol. 51, pp. 728-734, 2022.

[19] B. Gugulothu, P. S. S Kumar, B. Srinivas, A. Ramakrishna, and S. Vijayakumar, "Investigating the material removal rate parameters in ECM for Al 5086 alloy-reinforced silicon carbide/flyash hybrid composites by using minitab-18," Advances in Materials Science and Engineering, vol. 2021, pp. 1-6, 2021.

[20] R. Srinivasan and V. Vijayan, "Optimal ordering strategy pricing model with worsening materials in fuzzy environment," Materials Today: Proceedings, vol. 21, pp. 158-163, 2020.

[21] R. Srinivasan, N. Karthikeyan, K. Renganathan, and D. V. Vijayan, "Method for solving fully fuzzy transportation problem to transform the materials," Materials Today: Proceedings, vol. 37, pp. 431-433, 2021. 